Review

\title{
Fundus Autofluorescence and RPE Lipofuscin in Age-Related Macular Degeneration
}

\section{Janet R. Sparrow ${ }^{1,2, *}$ and Tobias Duncker ${ }^{1}$}

1 Department of Ophthalmology, Columbia University Medical Center, 635 W. 165th Street, New York, NY 10032, USA; E-Mail: tobias.duncker@gmail.com

2 Department of Pathology and Cell Biology, Columbia University Medical Center, 630 168th Street, New York, NY 10032, USA

* Author to whom correspondence should be addressed; E-Mail: jrs88@columbia.edu; Tel.: +1-212-305-0044.

External Editor: Margaret DeAngelis

Received: 28 August 2014; in revised form: 4 November 2014 / Accepted: 6 November 2014 / Published: 17 November 2014

\begin{abstract}
Genes that increase susceptibility to age-related macular degeneration (AMD) have been identified; however, since many individuals carrying these risk alleles do not develop disease, other contributors are involved. One additional factor, long implicated in the pathogenesis of $A M D$, is the lipofuscin of retinal pigment epithelium (RPE). The fluorophores that constitute RPE lipofuscin also serve as a source of autofluorescence (AF) that can be imaged by confocal laser ophthalmoscopy. The AF originating from lipofuscin is excited by the delivery of short wavelength (SW) light. A second autofluorescence is emitted from the melanin of RPE (and choroid) upon near-infrared (NIR-AF) excitation. SW-AF imaging is currently used in the clinical management of retinal disorders and the advantages of NIR-AF are increasingly recognized. Here we visit the damaging properties of RPE lipofuscin that could be significant when expressed on a background of genetic susceptibility. To advance interpretations of disease-related patterns of fundus AF in AMD, we also consider the photochemical and spectrophotometric features of the lipofuscin compounds responsible for generating the fluorescence emission.
\end{abstract}

Keywords: retinal pigment epithelium; bisretinoid; melanin; lipofuscin; fundus autofluorescence; near-infrared fluorescence; short-wavelength fluorescence imaging 


\section{Introduction}

Age-related macular degeneration (AMD) is a complex disorder that is influenced by genetic and environmental factors; heritability is estimated to account for $45 \%$ to $71 \%$ of cases $[1,2]$. Several $(\sim 20)$ AMD genetic susceptibility genes have been identified with two loci, complement factor $\mathrm{H}(\mathrm{CFH}$ (1q32) and age-related maculopathy susceptibility 2/HtrA serine peptidase 1 (ARMS2/HTRA1) on $10 \mathrm{q} 26$ accounting for $50 \%$ of AMD cases $[3,4]$. The CFH locus harbors many independent risk and protective haplotypes [5,6] while for ARMS2/HTRA1 a single major risk haplotype is associated with AMD [7]. Multiple studies have also demonstrated that haplotype-tagging single-nucleotide polymorphisms (SNPs) in CFH and ARMS2, are major determinants of AMD endophenotypes and disease progression [8]. Specifically, CFH-rs1061170 is associated with drusen and with both early and advanced AMD while ARMS2-rs10490924 is strongly associated with reticular pseudodrusen and rapid progression to late AMD [5,7-9]. Nevertheless, by various estimates, currently known genetic loci account for only $50 \%-75 \%$ of overall AMD risk. Interest in a role for retinal pigment epithelium (RPE) lipofuscin in AMD stems from the knowledge that it accumulates with age [10,11], is high in central retina [11], exhibits behaviors toxic to RPE [12-15] and exhibits a link to drusen formation [16].

\section{RPE Lipofuscin as the Source of Short-Wavelength (SW)-Fundus Autofluorescence}

Advances in non-invasive fundus imaging have facilitated the diagnosis and differentiation of retinal disease. In vivo imaging provides a window within which to view the natural course of retinal disease. Of the available imaging modalities, fundus autofluorescence (AF) has proven to be especially valuable, in large part because disease-related processes can alter the distribution of the AF signal. Accordingly, recognizable disease phenotypes are often produced.

The natural autofluorescence of the fundus that is excited by SW light (488 nm excitation) (Figure 1) exhibits spectral features and an age-relationship that indicates a principle origin from the fluorescent pigments that accumulate in RPE cells as lipofuscin [17]. Unlike lipofuscin species that accumulate in other non-dividing cells, the pigments of RPE lipofuscin are produced in the membranes of photoreceptor outer segments from non-enzymatic reactions of vitamin A aldehyde [18-21]. This fluorescent material is transferred to RPE cells within phagocytosed outer segment disks [22,23] and becomes deposited in the lysosomal compartment of the cells. In the healthy retina, fundus autofluorescence increases linearly with age although subjects vary in terms of intensities [11]. The age-related increase levels off after age 70 perhaps because of a loss of photoreceptor or RPE cells [24] and/or changes in fluorescence emission due to extensive photooxidation/photodegradation of the bisretinoid compounds [25] (discussed below).

RPE lipofuscin consists of a complex mixture of fluorophores that have been identified in by chromatography and mass spectrometry and characterized structurally; all of the known bisretinoid lipofuscin pigments have been detected in human eyes [26] (Figure 2). These fluorophores include the pyridinium-containing molecules A2-glycerophosphoethanolamine (A2-GPE) [27], A2E and isomers of A2E [28-36], dimers of all-trans-retinal having a cyclohexadiene head group (all-trans-retinal dimer) [33,37] and the associated protonated Schiff base conjugate [37] and the uncharged A2-DHP-PE (A2-dihydropyridine-phosphatidylethanolamine) [38]. Higher molecular weight adducts also form 
when aldehyde-bearing cleavage products of bisretinoid react with intact bisretinoid molecules [39]. Other molecular constituents of RPE lipofuscin are adducts of CEP (2-( $\omega$-carboxyethyl)-pyrrole) [40], HNE (4-hydroxynonenal) and MDA (malondialdehyde) [41] that are derived from oxidative fragmentation of lipid. Products of lipid oxidation are generally non-fluorescent or blue-emitting fluorophores $[42,43]$ and in this case could be generated by the photoreactivity of other lipofuscin fluorophores. Little or no protein is present in RPE lipofuscin [40]. Accumulation of bisretinoids in RPE cells is unlikely to depend on an inhibition of lysosomal enzyme activity, since this fluorescent material is amassed in all healthy eyes beginning at early ages [44].

Figure 1. Short-wavelength (SW-AF) and near-infrared (NIR-AF) fundus autofluorescence. Images were obtained with $488 \mathrm{~nm}$ (SW) and $787 \mathrm{~nm}$ (NIR) excitation.
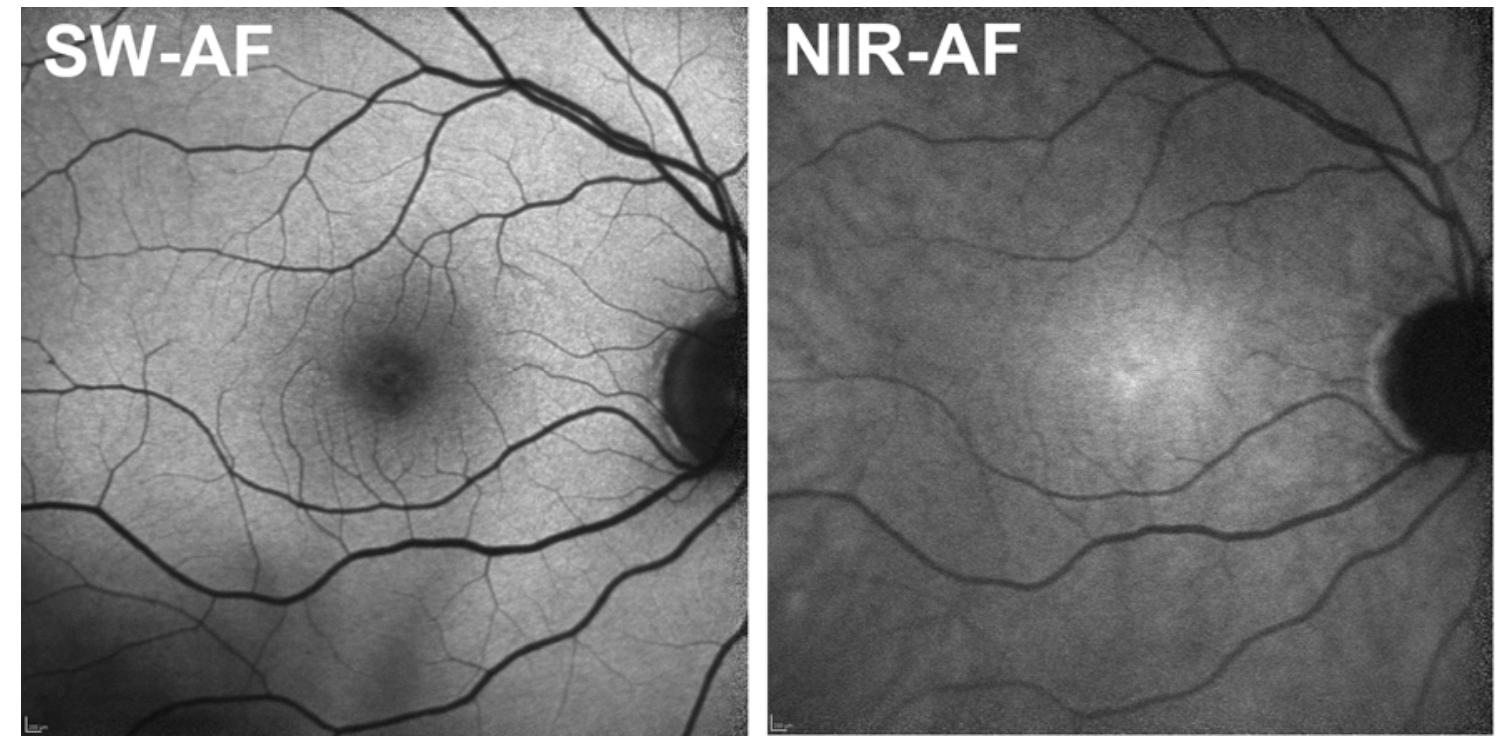

Figure 2. Structures and absorbance maxima $\left(\lambda_{\max }\right)$ of some bisretinoid fluorophores in retinal pigment epithelium (RPE) lipofuscin. Absorbance maxima can be assigned to each of the side-arms of the molecules.

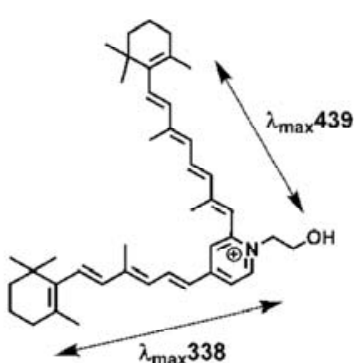

A2E

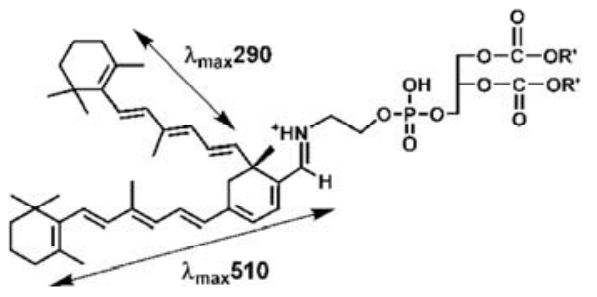

all-trans-retinal dimer-PE

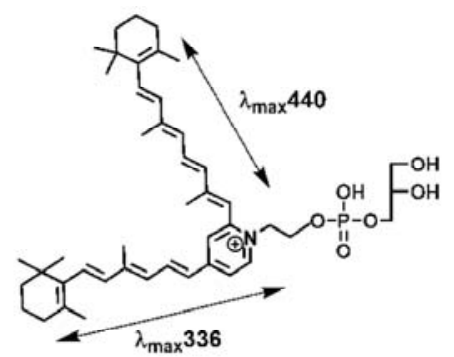

A2GPE

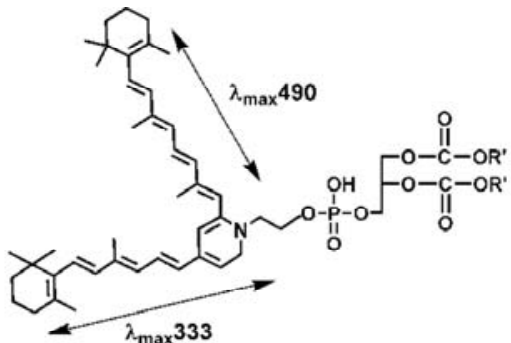

A2-DHP-PE

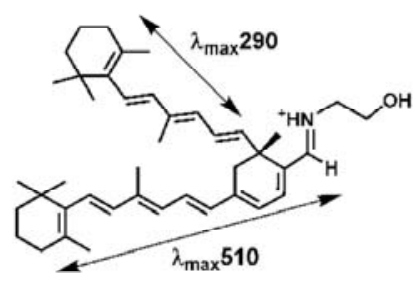

all-trans-retinal dimer-E

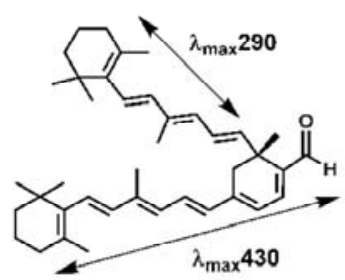

all-trans-retinal dimer 
The various bisretinoids of RPE lipofuscin have some common structural features (Figure 2). They present with a central six-carbon ring from which extend two polyene arms terminating in $\beta$ ionone rings. Each of these arms is derived from a molecule of retinaldehyde and constitutes a separate light-absorbing chromophore, one arm absorbing in the ultraviolet range and the other in the visible (Figure 2). The numbers of alternating carbon-carbon double and single bonds that form the conjugation systems of the arms determine the wavelength of absorbance; the longer conjugation system in each molecule confers absorbance in the visible range. Absorbances in the visible spectrum are significant since these wavelengths reach the retina. Since these adducts of retinaldehyde are held together by covalent bonds, bisretinoids do not provide stores of retinoid for the visual cycle, as has been suggested [45].

\section{Spectral Signatures of SW-Fundus AF and RPE Lipofuscin}

In clinical settings, SW-fundus AF is excited by wavelengths ranging from $488 \mathrm{~nm}$, the excitation employed with a confocal scanning laser ophthalmoscope (cSLO), to the 535-580 $\mathrm{nm}$ range utilized by a modified fundus camera [46] and the $568 \mathrm{~nm}$ light used with fluorescence adaptive optics ophthalmoscopy $[17,47,48]$. Fundus autofluorescence measured in vivo by spectrophotometry has a broad excitation spectrum that peaks between $490-510 \mathrm{~nm}$. The fluorescence emission is also broad and centered at approximately $600 \mathrm{~nm}[11,17]$. RPE lipofuscin ex vivo exhibits an excitation spectrum that peaks between $450-490 \mathrm{~nm}$; the fluorescence emission is maximal at $\sim 600 \mathrm{~nm}$ [49] (Figure 3). Moreover, just as with fundus autofluorescence, the emission spectrum recorded from whole lipofuscin exhibits red-shifts when excited by progressively longer wavelengths [49] (Figure 3). Thus the spectral characteristics of fundus autofluorescence are consistent with that of RPE lipofuscin $[43,50-52]$ and chiefly with an origin from the bisretinoid fluorescent pigments that are known constituents of RPE lipofuscin. The bisretinoids that have been characterized have absorbance maxima varying from $440 \mathrm{~nm}$ to $510 \mathrm{~nm}$ and they emit with an orange fluorescence that peaks at $\sim 600 \mathrm{~nm}$ [26]. The bisretinoid A2E can emit fluorescence at longer wavelength excitations such as $545 \mathrm{~nm}$ (Figure 3B).

Figure 3. Fluorescence emission spectra of human RPE lipofuscin and A2E (in PBS with $2 \%$ DMSO). Emission was recorded at excitation wavelengths 436, 480 and $545 \mathrm{~nm}$ as published [49]. Emission maxima are indicated.
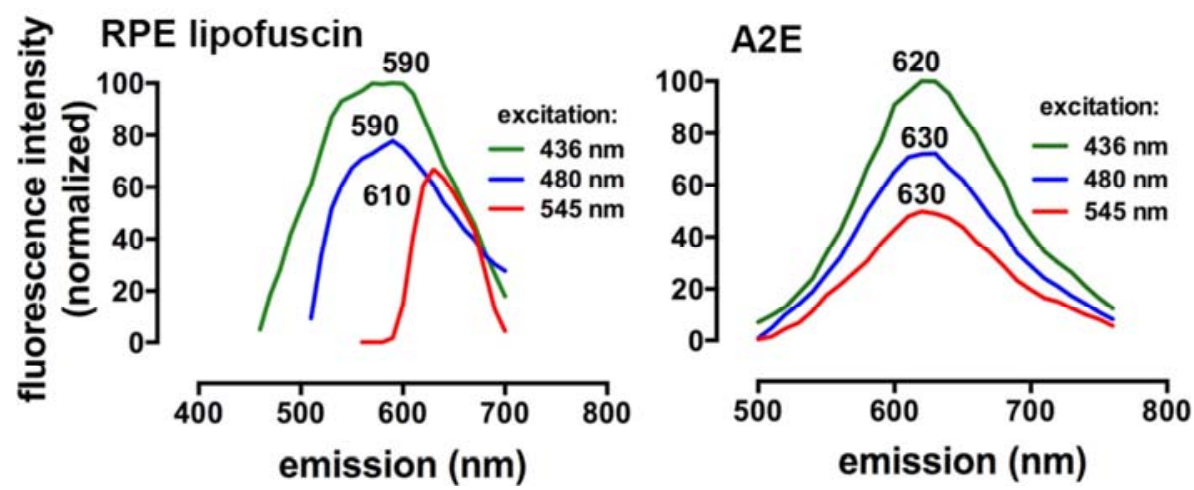


\section{Photoreactive Properties of RPE Lipofuscin and the Implications for Fundus AF}

While there exists no evidence that bisretinoids of RPE lipofuscin can undergo lysosomal degradation, loss of this material due to photodegradation has been demonstrated. Thus studies of RPE lipofuscin [53-55] and individual bisretinoid lipofuscin fluorophores such as A2-GPE, all-trans-retinal dimer and A2E have revealed that these compounds are photoinducible generators of reactive oxygen species such as singlet oxygen and superoxide anion. Singlet oxygen in turn reacts with the conjugated double bond systems comprising the arms of the bisretinoid molecules [56-61] leading to the fragmentation of the parent molecules and release of aldehyde-bearing cleavage products such as methylgloxal and glyoxal [60] that can react with and inactivate proteins. These small dicarbonyls also provoke the formation of advanced glycation end products (AGE) that deposit extracellularly [16,62].

AGEs incite inflammatory processes and since they are detected in drusen [63,64], they reflect a link between RPE bisretinoid lipofuscin and the formation of sub-RPE deposits. Photooxidation of A2E and all-trans-retinal dimer has also been shown to incite complement activation $[65,66]$.

Photooxidation is clearly an ongoing process in the eye since photooxidized forms of A2E and all-trans-retinal dimer have been detected in isolated human and mouse RPE [25,57]. These processes likely contribute to Bruch's membrane thickening [67] and photoreceptor cell degeneration [68,69] in Abca 4 mutant mice and are a cause of the increased vulnerability of albino Abca $4^{-1-}$ mice to retinal light damage [70].

The propensity for bisretinoids to undergo photooxidative and photodegradative processes may underlie the decline in RPE lipofuscin fluorescence emission (photobleaching) that has been observed in non-human primates during in vivo fluorescence imaging by adaptive optics scanning laser ophthalmoscopy [48,71], with cell culture models [72] and in non-cellular assays (Figure 4). Lipofuscin photobleaching may also explain why after surgical repair of some cases of retinal detachment, hyperautofluorescent lines coursing parallel to retinal blood vessels can be visible in fundus AF images [73,74] (Figure 5). The hyperautofluorescent imprint has been interpreted as indicating a change in the position of the vessel relative to the underlying retinal tissue and is visible because of contrasting levels of AF brightness. At any given time, the intensity of fundus AF is likely the difference between fluorophore synthesis on the one hand, and lipofuscin photoxidation/ photodegradation in RPE, on the other. Under the shadow of a blood vessel, the formation of bisretinoid from retinaldehyde (with 11-cis being converted to all-trans-retinal) would likely continue unabated [20,30,75-77] but lipofuscin photooxidation and photobleaching would be substantially reduced. As a result, a vessel imprint of more intense AF would be revealed upon retinal translocation. 
Figure 4. A2E photobleaching by irradiation at $480 \mathrm{~nm}$ for 4 and $8 \mathrm{~min}$. Fluorescence intensity decreases with irradiation and the emission maximum undergoes a hypsochromic shift. Emission peak wavelengths $(\mathrm{nm})$ are indicated adjacent to each trace.

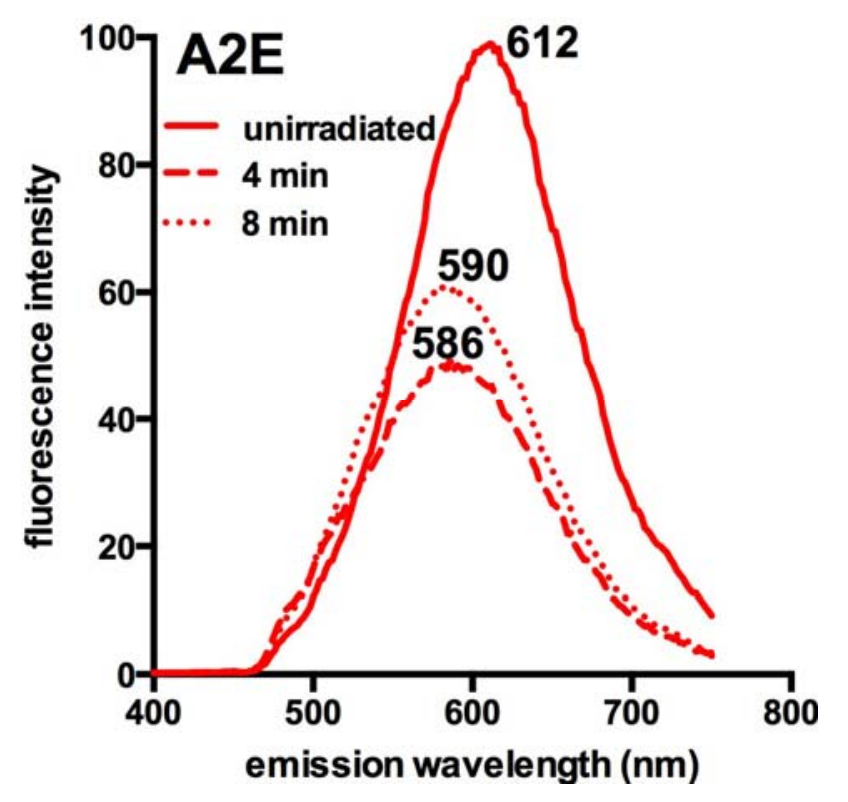

Figure 5. Fundus autofluorescence image of an individual following retinal detachment repair. Hyperautofluorescent lines follow a course that parallels the retinal vessels below.

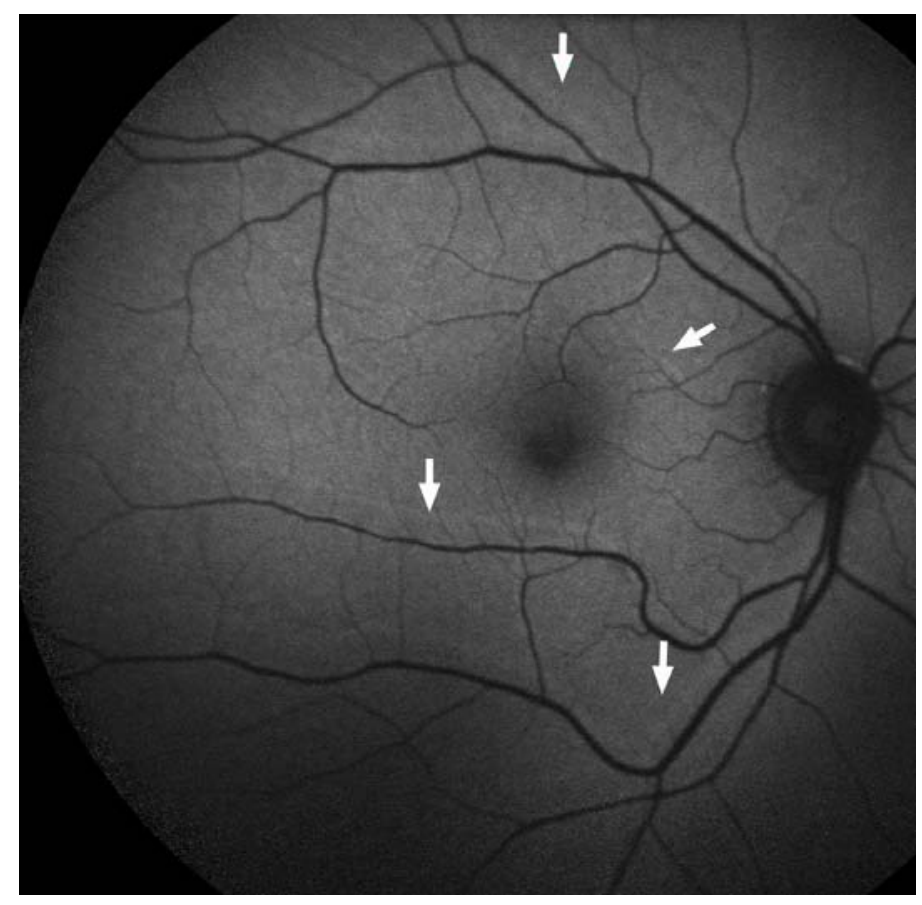

\section{Topographic Distribution of SW-AF in Healthy Eyes}

When RPE lipofuscin is assayed by recording fluorescence in histological sections of human retina, the signal is found to increase from central fovea to perifovea and after peaking at an eccentricity of $\sim 8^{\circ}$, it decreases towards the periphery $[10,78]$. A similar pattern has been observed with quantitative fundus autofluorescence (qAF) (Figure 6); at an eccentricity of $10^{\circ}$, qAF is approximately $95 \%$ of that 
measured centrally [79]. Reduced foveal fundus autofluorescence is due in large part to absorption of the exciting light by macular pigment and to the higher optical density of melanin in central RPE [17]. By fundus spectrophotometry, qAF and fluorescence photomicroscopy [45], the highest levels of RPE lipofucin in healthy eyes have been observed perifoveally in superior-temporal retina (Figure 6) [44]. Unexpectedly, this pattern was not replicated in another study relying on fluorescence measurements in flat-mounted human cadaver eyes [80].

Figure 6. Quantitative fundus autofluorescence (qAF) in healthy human eyes. Short-wavelength fundus AF images (top row) and corresponding color-coded qAF images (bottom row) at the ages indicated. Lower qAF values are coded in blue and higher qAF values as orange (color scale). Fundus autofluorescence intensities increase with age and the highest levels occur in superior-temporal fundus.

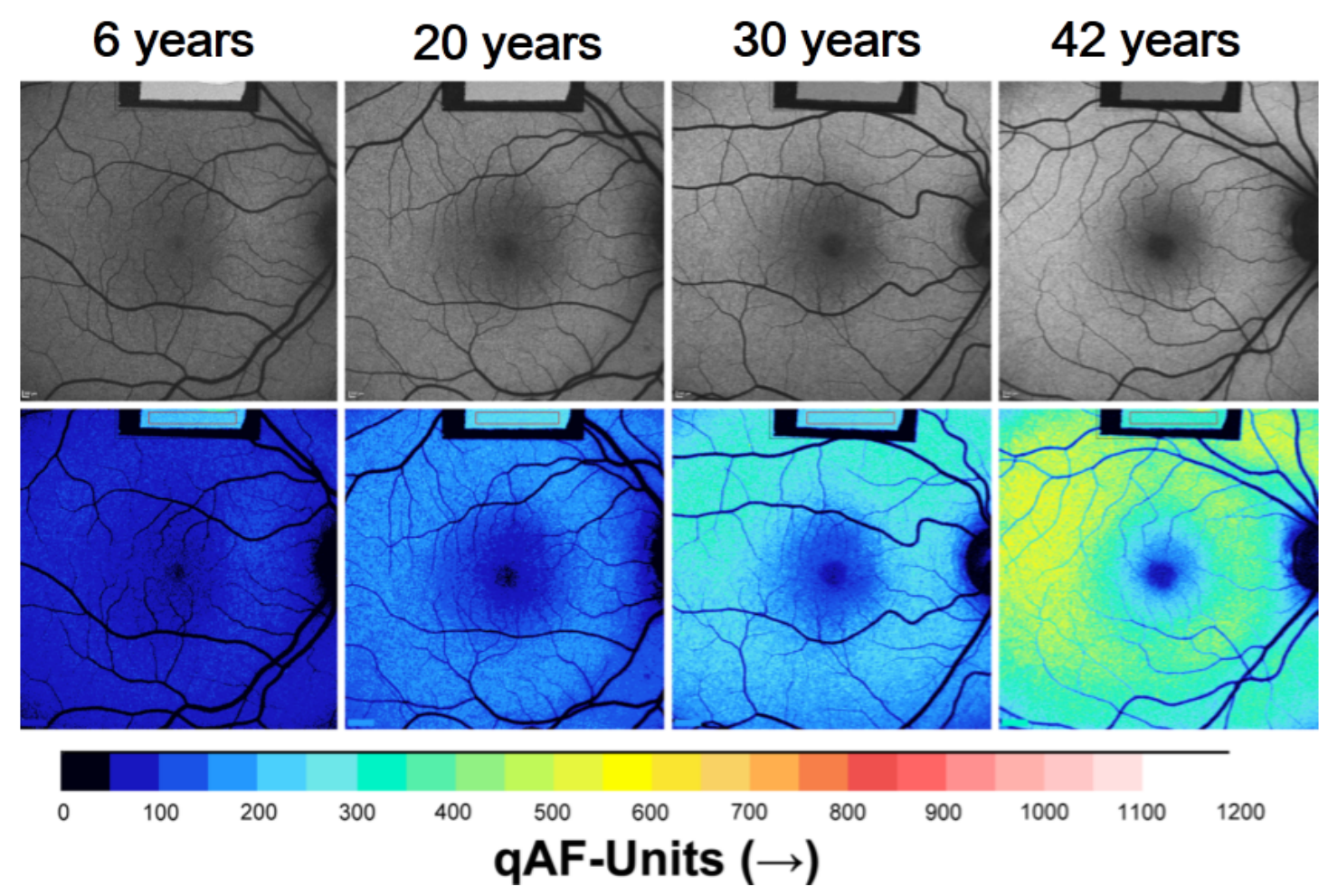

Based on the spatial distribution of mass peaks detected with matrix-assisted laser desorption-ionization imaging mass spectrometry (MALDI-MS) investigators have reported that A2E is detectable in central retina of mice [81], but not in the central human RPE [36]. Instead, the highest A2E levels were restricted to a small patch of RPE found exclusively in the far periphery of temporal retina [80]. This patch was not matched by similar A2E signal in in the periphery of superior, nasal or inferior retina. While A2E is well known to be fluorescent, surprisingly, this patch was almost devoid of fluorescence.

Since the spectral features of RPE lipofuscin and fundus autofluorescence are best accounted for by the excitation and emission spectra of the bisretinoid constituents, the fluorescence originating in centrally situated RPE cells likely originates from some combination of these di-retinal adducts. Interestingly, the MALDI-MS findings could indicate that the various species of bisretinoid lipofuscin compounds exhibit spatial heterogeneity. Reduced levels of A2E in the macula could also be a consequence of greater lipofuscin photocleavage in central RPE; an explanation such as this could 
account for the greater susceptibility of the macula to disease. Failure to detect A2E centrally, may even be attributable to the limitations of the methodology. MALDI-MS is a surface-based technique that depends on the extraction of analyte into a matrix applied to the surface of the tissue. Factors that could cause spatial differences in extraction efficiency are regional differences in RPE height and spatial differences in the compartmentalization of lipofuscin. For instance RPE cells are taller and narrower in the human macula [78] with melanin being uppermost and lipofuscin at greater depths in the cells. After age 50 complex organelles containing both melanin and lipofuscin (melanolipofuscin) predominate in the cells [78] with macular RPE containing more melanolipofuscin than RPE at the equator and periphery [82]. Lipofuscin is less extractable from the RPE of these older eyes [83]. Thus it is likely that the extraction from central RPE is less efficient because of the depths of lipofuscin in the cells and/or difficulty in accessing lipofuscin from complex melanolipofuscin-organelles.

\section{NIR-AF in the Healthy Eye}

The healthy fundus also exhibits a near-infrared autofluorescence (NIR-AF) $(>800 \mathrm{~nm}$ ) when excited at $\sim 787 \mathrm{~nm}[84,85]$ (Figure 1). The intensity of the fundus NIR-AF is at least 60 times less than SW-AF [86]. Several lines of evidence indicate that RPE and choroidal melanin serve as a source of the NIR-AF signal. For instance, melanin is known to fluoresce under near-infrared light excitation [87]. Additionally, the high NIR-AF signal at the fovea corresponds [86] to the elevated optical density of melanin in this area [78]. Melanocytic choroidal nevi also fluoresce brightly with NIR-AF imaging. Conversely, NIR-AF emanating from a full-thickness macular hole is similar in brightness to surrounding retina [86].

The more frequent use of SW-AF may be due, in part, to the introduction of the Heidelberg Spectralis having optical coherence tomography (OCT) capability (HRA + OCT) and to the subsequent decline in the popularity of the HRA2 and Spectralis HRA in retinal clinics. The OCT module in the Spectralis reduces NIR-AF signal intensity, thus compromising NIR-AF image quality as compared to cSLOs without OCT (e.g., HRA2 and Spectralis HRA). Nevertheless, NIR-AF has advantages over SW-AF. For instance, during image acquisition, patients are not disturbed by the NIR-AF light as they are with the SW-AF exciting light. This improves patient cooperation, especially in young children and photophobic patients.

\section{Comparison of SW- and NIR-AF in AMD: Altered Intensities and Aberrant Patterns}

In the presence of retinal disease such as AMD, patterns and intensities of fundus autofluorescence are notably altered [88-93]. At locations of RPE and photoreceptor cell demise (atrophy) both the SW-AF and NIR-AF signals become strikingly deficient or absent [94,95]. These areas of atrophy can take the form of discrete spots, isolated patches or large expanses (geographic atrophy, GA, USA). Loss of the RPE cell monolayer in GA has been confirmed by OCT [96]. While GA presents as areas of darkness in both SW and NIR-AF (Figure 7), the lesion size can sometimes appear larger with either the SW-AF or NIR-AF modality [84,97] (Figure 7). Nevertheless, the rate of increase in GA area is the same whether measured in SW- or NIR-AF images [98]. In exudative AMD, the developing neovascular lesion can be discerned in SW-AF images early on as a focal hyperautofluorescence [99]. 
Later the SW-AF signal is reduced within the lesion $[99,100]$. In some cases the edge of the neovascular lesion exhibits increased SW-AF signal [100].

In the zone of retina immediately adjacent to geographic atrophy, there are often additional AF changes. These aberrant signals can present as intermittent foci or continuous bands of altered brightness in both SW-AF and NIR-AF images [101-103]. In these junctional zones areas of increased SW-AF can coincide with increased NIR-AF; increased SW-AF can overlap with reduced NIR-AF; or NIR-AF signal can be enhanced while SW-AF may appear normal [84,104] (Figure 7). Interestingly, a loss of photoreceptor function was found to be associated with both increased and decreased NIR-AF [97,105].

Since both SW-AF and NIR-AF are considered to originate in RPE cells, it is puzzling that SW-AF can be increased at positions where NIR-AF is reduced or absent. This apparent incongruity has been attributed to abnormal RPE cells that have lost melanin while accumulating excessive levels of lipofuscin due to accelerated rates of outer segment phagocytosis [84,105]. However, lipofuscin production is not dependent on the rate of phagocytosis. The lipofuscin forms in photoreceptor cells prior to disc shedding and phagocytosis. As is evident from studies of the RCS rat, the fluorophores of lipofuscin form and accumulate in photoreceptor outer segment debris even in the absence of phagocytosis [106-108].

Other observations indicate that photoreceptor cells are likely to be degenerating in these junctional zones of increased SW-AF. In particular, retinal sensitivity, measured by microperimetry, is commonly reduced at positions presenting with increased SW-AF as compared to normal SW-AF [105,109]. In addition, OCT findings in the zone of enhanced autofluorescence surrounding GA include thinning of the reflective band attributable to RPE/Bruch's membrane and disruption of the reflectivity band corresponding to the ellipsoid zone of photoreceptor inner segments $[96,110]$ Thus could it be that at positions of diminished NIR-AF, RPE cells are atrophied or lost and impaired photoreceptor cells become a source of accelerated lipofuscin formation and thus enhanced SW-AF? Mechanistically, mishandling of retinaldehyde, the precursor of lipofuscin, is known to lead to elevated bisretinoid formation in photoreceptor cells [111] and compromised photoreceptor cells may not be able to provide the energy needed for reduction of retinaldehyde to the non-reactive alcohol form. Similar mechanisms may explain the rapid onset of elevated fundus SW-AF that co-localizes with scotomas associated with acute macular neuroretinopathy (AMN) [93,112].

The observation that NIR-AF signals increase in parallel with increases in SW-AF at the border of GA may also not be fully understand. Hyperautofluorescence foci at the junctional zone of GA, at least in some cases, can be attributed to abnormally superimposed RPE cells [113,114]. But whether this can account for more extensive bands of high NIR-AF [84] is not certain. It has been suggested that RPE lipofuscin may contribute to NIR-AF of the fundus [86]. However, albino rats do not exhibit NIR-AF despite the presence of lipofuscin [115] and as shown in Figure 8, we have not detected an NIR-AF signal from synthesized samples of A2E that otherwise emit fluorescence when excited at $488 \mathrm{~nm}$. NIR-AF emission from other bisretinoids is unlikely, given the small structural differences amongst these compounds (Figure 2). If melanogenesis is the basis for increased NIR-AF brightness at the border of GA, as has been suggested [84,105], one might expect that increased melanin concentrations would be visible as hyperpigmented spots and bands in color fundus photographs. In considering an optical effect as an explanation for increased NIR-AF signal it could be that RPE lipofuscin does not 
fluoresce in the NIR range but can modify the NIR-AF emission from melanin. This could occur if lipofuscin secondary lysosomes intercalate amongst apically situated melanosomes [78,116] thereby reducing the NIR-AF quenching associated with secondary self-absorbance of the fluorescence emission. A mechanism such as this might also explain why hyperautofluorescent rings visible in the NIR-AF fundus images in retinitis pigmentosa exhibit spatial correspondence with high intensity rings observed in SW-AF images [117].

Figure 7. An area of geographic atrophy (GA) imaged with short-wavelength (SW) and near-infrared (NIR) autofluorescence (AF) imaging. GA appears dark with both modalities. The zone surrounding GA is hyperautofluorescent in the NIR-AF image while having relatively normal SW-AF signal. When vessel landmarks are used as a guide (arrows), total lesion size appears larger in the NIR-AF image.
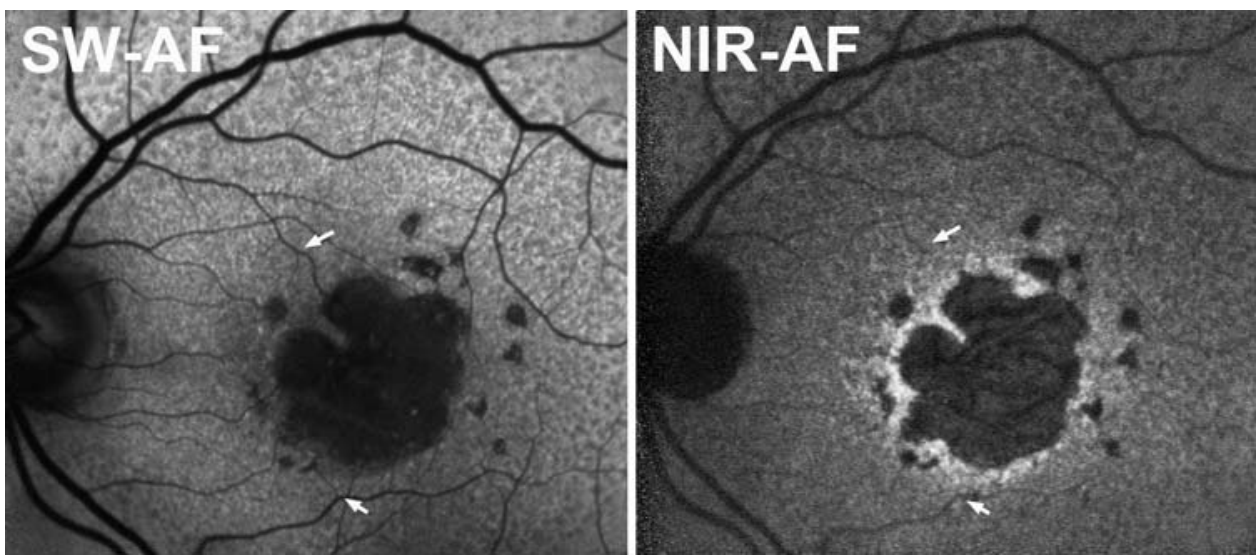

Figure 8. Synthesized A2E imaged with a confocal scanning laser ophthalmoscope (HRA2; Heidelberg Engineering, Heidelberg, Germany) using $488 \mathrm{~nm}$ (SW-AF) and $787 \mathrm{~nm}$ (NIR-AF) excitation. No signal was generated with the NIR excitation.

\section{A2E}

\section{SW-AF NIR-AF}

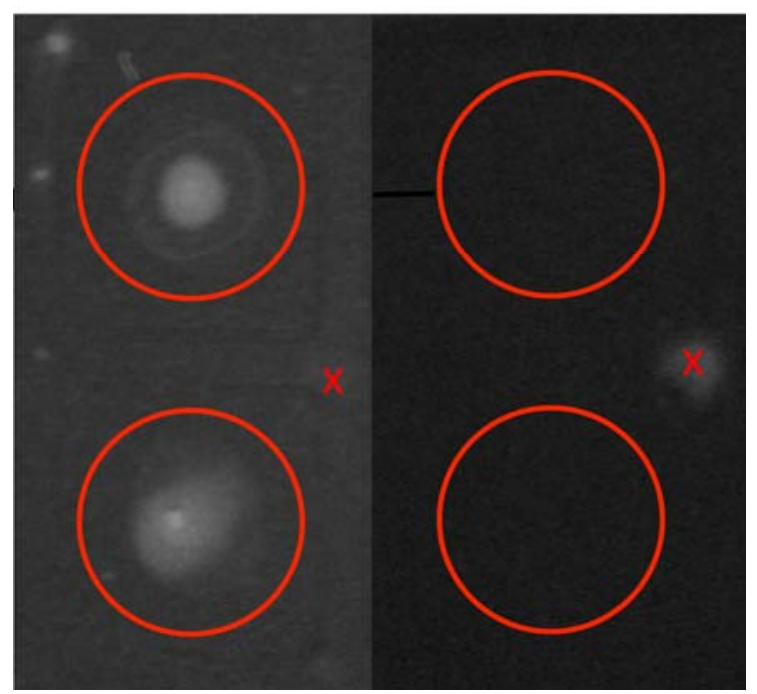




\section{Conclusions}

Interest in a role for RPE lipofuscin in AMD stems from its age-related increase [10,11], an accumulation that is more pronounced in central retina [11], a propensity for adverse effects on RPE and photoreceptor cells [12-15,68,70] and links to drusen formation [16,67]. Contributions to AMD susceptibility from RPE lipofuscin would exist within the context of background genetic risk. Thus extrapolation from aging eyes in the absence of disease may not be informative [45].

Since the products of bisretinoid photodegradation can be damaging $[16,60]$, it is worth considering whether lipofuscin lost by photooxidation/photodegradation is more significant than the lipofuscin remaining in the cells. At any given time, the lipofuscin in RPE that is recorded by SW-AF may consist of only some portion of the fluorescent material that has been accumulated over a life-time. SW-AF emitted from RPE bisretinoids is commonly regarded as a way to monitor the health of the RPE, with areas of high AF indicating increased lipofuscin levels and areas of low AF indicating RPE loss. However, as discussed here there is increasing evidence that interpretations of the SW-AF signal are complex. For instance, impaired photoreceptors may generate increased levels of bisretinoid fluorophores thus amplifying SW-AF signal. Ultimately, an understanding of patterns of fundus AF will impact the use of these images to assess therapeutic outcomes.

While fundus autofluorescence provides en face spatial information, the spectral features of the fluorescence are not elucidated and the cellular origin of the fluorescence is not identified. Recently, however, methods have been developed for quantifying SW-AF. This approach has been shown to enable the differentiation of similar phenotypes having disparate genetic origins [44,118]. The qAF approach may eventually help to ascertain the role of lipofuscin in various retinal disorders including AMD. Because of more limited gradations of signal and thus greater contrast, diseased versus non-diseased areas of retina are easier to distinguish in NIR-AF images as compared to SW-AF images. Indeed, in recessive Stargardt disease (STGD1), SW-AF changes are often not obvious at fundus locations where abnormalities are detectable in NIR-AF images [119]. In addition, in many cases the low NIR-AF signal corresponds spatially to loss of the inner segment ellipsoid zone (EZ) in spectral domain (SD) OCT images [119]. This relationship is important since EZ integrity is essential for visual function [120]. While the origin of the NIR-AF signal may not be completely understood, the NIR-AF signal can provide a good estimate of the size of geographic atrophy and surrounding abnormalities. All of these issues favor the inclusion of NIR-AF in the management of retinal diseases such as AMD.

\section{Acknowledgments}

The work was supported by grants from the National Eye Institute (RO1EY12951; RO1EY024091; P30EY019007) Foundation Fighting Blindness and by a grant from Research to Prevent Blindness to the Department of Ophthalmology, Columbia University.

\section{Author Contributions}

Janet Sparrow prepared the manuscript and figures. Tobias Duncker critically read the manuscript. 


\section{Conflicts of Interest}

The authors have no conflicts of interest to declare.

\section{References}

1. Gorin, M.B. Genetic insights into age-related macular degeneration: Controversies addressing risk, causality, and therapeutics. Mol. Aspects Med. 2012, 33, 467-486.

2. Seddon, J.M.; Cote, J.; Page, W.F.; Aggen, S.H.; Neale, M.C. The US twin study of age-related macular degeneration: Relative roles of genetic and environmental influences. Arch. Ophthalmol. 2005, 123, 321-327.

3. Fisher, S.A.; Abecasis, G.R.; Yashar, B.M.; Zareparsi, S.; Swaroop, A.; Iyengar, S.K.; Klein, B.E.K.; Klein, R.; Lee, K.E.; Majewski, J.; et al. Meta-analysis of genome scans of age-related macular degeneration. Hum. Mol. Genet. 2005, 14, 2257-2264.

4. Klein, R.J.; Zeiss, C.; Chew, E.Y.; Tsai, J.Y.; Sackler, R.S.; Haynes, C.; Henning, A.K.; SanGiovanni, J.P.; Mane, S.M.; Mayne, S.T.; et al. Complement factor H polymorphism in age-related macular degeneration. Science 2005, 308, 385-389.

5. Hageman, G.S.; Anderson, D.H.; Johnson, L.V.; Hancox, L.S.; Taiber, A.J.; Hardisty, L.I.; Hageman, J.L.; Stockman, H.A.; Borchardt, J.D.; Gehrs, K.M.; et al. A common haplotype in the complement regulatory gene factor $\mathrm{H}(\mathrm{HF} 1 / \mathrm{CFH})$ predisposes individuals to age-related macular degeneration. Proc. Natl. Acad. Sci. USA 2005, 102, 7227-7232.

6. Hughes, A.E.; Orr, N.; Esfandiary, H.; Diaz-Torres, M.; Goodship, T.; Chakravarthy, U. A common CFH haplotype, with deletion of CFHR1 and CFHR3, is associated with lower risk of age-related macular degeneration. Nat. Genet. 2006, 38, 1173-1177.

7. Rivera, A.; Fisher, S.A.; Fritsche, L.G.; Keilhauer, C.N.; Lichtner, P.; Meitinger, T.; Weber, B.H. Hypothetical LOC387715 is a second major susceptibility gene for age-related macular degeneration, contributing independently of complement factor $\mathrm{H}$ to disease risk. Hum. Mol. Genet. 2005, 14, 3227-3236.

8. Farwick, A.; Dasch, B.; Weber, B.H.F.; Pauleikhoff, D.; Stoll, M.; Hense, H.-W. Variations in five genes and the severity of age-related macular degeneration: Results from the muenster aging and retina study. Eye 2009, 23, 2238-2244.

9. Farwick, A.; Wellman, J.; Stoll, M.; Pauleikhoff, D.; Hense, H.-W. Susceptibility genes and progression in age-related maculopathy: A study of single eyes. Invest. Ophthalmol. Vis. Sci. 2010, 51, 731-736.

10. Wing, G.L.; Blanchard, G.C.; Weiter, J.J. The topography and age relationship of lipofuscin concentration in the retinal pigment epithelium. Invest. Ophthalmol. Vis. Sci. 1978, 17, 601-607.

11. Delori, F.C.; Goger, D.G.; Dorey, C.K. Age-related accumulation and spatial distribution of lipofuscin in RPE of normal subjects. Invest. Ophthalmol. Vis. Sci. 2001, 42, 1855-1866.

12. Sparrow, J.R.; Nakanishi, K.; Parish, C.A. The lipofuscin fluorophore A2E mediates blue light-induced damage to retinal pigmented epithelial cells. Invest. Ophthalmol. Vis. Sci. 2000, 41, 1981-1989. 
13. Sparrow, J.R.; Parish, C.A.; Hashimoto, M.; Nakanishi, K. A2E, a lipofuscin fluorophore, in human retinal pigmented epithelial cells in culture. Invest. Ophthalmol. Vis. Sci. 1999, 40, 2988-2995.

14. Finnemann, S.C.; Leung, L.W.; Rodriguez-Boulan, E. The lipofuscin component A2E selectively inhibits phagolysosomal degradation of photoreceptor phospholipid by the retinal pigment epithelium. Proc. Natl. Acad. Sci. USA 2002, 99, 3842-3847.

15. De, S.; Sakmar, T.P. Interaction of A2E with model membranes. Implications to the pathogenesis of age-related macular degeneration. J. Gen. Physiol. 2002, 120, 147-157.

16. Yoon, K.D.; Yamamoto, K.; Ueda, K.; Zhou, J.; Sparrow, J.R. A novel source of methylglyoxal and glyoxal in retina: Implications for age-related macular degeneration. PLoS One 2012, 7, e41309.

17. Delori, F.C.; Dorey, C.K.; Staurenghi, G.; Arend, O.; Goger, D.G.; Weiter, J.J. In vivo fluorescence of the ocular fundus exhibits retinal pigment epithelium lipofuscin characteristics. Invest. Ophthalmol. Vis. Sci. 1995, 36, 718-729.

18. Eldred, G.E.; Katz, M.L. Fluorophores of the human retinal pigment epithelium: Separation and spectral characterization. Exp. Eye Res. 1988, 47, 71-86.

19. Katz, M.L.; Eldred, G.E.; Robison, W.G., Jr. Lipofuscin autofluorescence: Evidence for vitamin a involvement in the retina. Mech. Ageing Dev. 1987, 39, 81-90.

20. Ben-Shabat, S.; Parish, C.A.; Vollmer, H.R.; Itagaki, Y.; Fishkin, N.; Nakanishi, K.; Sparrow, J.R. Biosynthetic studies of A2E, a major fluorophore of RPE lipofuscin. J. Biol. Chem. 2002, 277, 7183-7190.

21. Liu, J.; Itagaki, Y.; Ben-Shabat, S.; Nakanishi, K.; Sparrow, J.R. The biosynthesis of A2E, a fluorophore of aging retina, involves the formation of the precursor, A2-PE, in the photoreceptor outer segment membrane. J. Biol. Chem. 2000, 275, 29354-29360.

22. Katz, M.L.; Drea, C.M.; Eldred, G.E.; Hess, H.H.; Robison, W.G., Jr. Influence of early photoreceptor degeneration on lipofuscin in the retinal pigment epithelium. Exp. Eye Res. 1986, 43, 561-573.

23. Young, R.W.; Bok, D. Participation of the retinal pigment epithelium in the rod outer segment renewal process. J. Cell. Biol. 1969, 42, 392-403.

24. Del Priore, L.V.; Kuo, Y.H.; Tezel, T.H. Age-related changes in human RPE cell density and apoptosis proportion in situ. Invest. Ophthalmol. Vis. Sci. 2002, 43, 3312-3318.

25. Kim, S.R.; Jang, Y.; Sparrow, J.R. Photooxidation of RPE lipofuscin bisretinoids enhanced fluorescence intensity. Vis. Res. 2010, 50, 729-736.

26. Sparrow, J.R.; Gregory-Roberts, E.; Yamamoto, K.; Blonska, A.; Ghosh, S.K.; Ueda, K.; Zhou, J. The bisretinoids of retinal pigment epithelium. Prog. Retin Eye Res. 2012, 31, 121-135.

27. Yamamoto, K.; Yoon, K.D.; Ueda, K.; Hashimoto, M.; Sparrow, J.R. A novel bisretinoid of retina is an adduct on glycerophosphoethanolamine. Invest. Ophthalmol. Vis. Sci. 2011, 52, 9084-9090.

28. Sakai, N.; Decatur, J.; Nakanishi, K.; Eldred, G.E. Ocular age pigment “A2E”: An unprecedented pyridinium bisretinoid. J. Am. Chem. Soc. 1996, 118, 1559-1560.

29. Ren, R.F.; Sakai, N.; Nakanishi, K. Total synthesis of the ocular age pigment A2E: A convergent pathway. J. Am. Chem. Soc. 1997, 119, 3619-3620. 
30. Parish, C.A.; Hashimoto, M.; Nakanishi, K.; Dillon, J.; Sparrow, J.R. Isolation and one-step preparation of $\mathrm{A} 2 \mathrm{E}$ and iso-A2E, fluorophores from human retinal pigment epithelium. Proc. Natl. Acad. Sci. USA 1998, 95, 14609-14613.

31. Weng, J.; Mata, N.L.; Azarian, S.M.; Tzekov, R.T.; Birch, D.G.; Travis, G.H. Insights into the function of rim protein in photoreceptors and etiology of stargardt's disease from the phenotype in abcr knockout mice. Cell 1999, 98, 13-23.

32. Kim, S.R.; Fishkin, N.; Kong, J.; Nakanishi, K.; Allikmets, R.; Sparrow, J.R. The Rpe65 Leu450Met variant is associated with reduced levels of the RPE lipofuscin fluorophores A2E and iso-A2E. Proc. Natl. Acad. Sci. USA 2004, 101, 11668-11672.

33. Maeda, A.; Maeda, T.; Golczak, M.; Palczewski, K. Retinopathy in mice induced by disrupted all-trans-retinal clearance. J. Biol. Chem. 2008, 283, 26684-26693.

34. Maeda, A.; Golczak, M.; Maeda, T.; Palczewski, K. Limited roles of Rdh8, Rdh12, and Abca4 in all-trans-retinal clearance in mouse retina. Invest. Ophthalmol. Vis. Sci. 2009, 50, 5435-5443.

35. Ablonczy, Z.; Smith, N.; Anderson, D.M.; Grey, A.C.; Spraggins, J.; Koutalos, Y.; Schey, K.L.; Crouch, R.K. The utilization of fluorescence to identify the components of lipofuscin by imaging mass spectrometry. Proteomics 2014, 14, 936-944.

36. Ablonczy, Z.; Higbee, D.; Anderson, D.M.; Dahrouj, M.; Grey, A.C.; Gutierrez, D.; Koutalos, Y.; Schey, K.L.; Hanneken, A.; Crouch, R.K. Lack of correlation between the spatial distribution of $\mathrm{A} 2 \mathrm{E}$ and lipofuscin fluorescence in the human retinal pigment epithelium. Invest. Ophthalmol. Vis. Sci. 2013, 54, 5535-5542.

37. Fishkin, N.; Sparrow, J.R.; Allikmets, R.; Nakanishi, K. Isolation and characterization of a retinal pigment epithelial cell fluorophore: An all-trans-retinal dimer conjugate. Proc. Natl. Acad. Sci. USA 2005, 102, 7091-7096.

38. Wu, Y.; Fishkin, N.E.; Pande, A.; Pande, J.; Sparrow, J.R. Novel lipofuscin bisretinoids prominent in human retina and in a model of recessive stargardt disease. J. Biol. Chem. 2009, 284, 20155-20166.

39. Murdaugh, L.S.; Mandal, S.; Dill, A.E.; Dillon, J.; Simon, J.D.; Gaillard, E.R. Compositional studies of human RPE lipofuscin: Mechanisms of molecular modifications. J. Mass Spectrom. 2011, 46, 90-95.

40. Ng, K.P.; Gugiu, B.G.; Renganathan, K.; Davies, M.W.; Gu, X.; Crabb, J.S.; Kim, S.R.; Rozanowska, M.B.; Bonilha, V.L.; Rayborn, M.E.; et al. Retinal pigment epithelium lipofuscin proteomics. Mol. Cell Proteomics 2008, 7, 1397-1405.

41. Schutt, F.; Bergmann, M.; Holz, F.G.; Kopitz, J. Proteins modified by malondialdehyde, 4-hydroxynonenal or advanced glycation end products in lipofuscin of human retinal pigment epithelium. Invest. Ophthalmol. Vis. Sci. 2003, 44, 3663-3668.

42. Rein, D.; Tappel, A.L. Fluorescent lipid oxidation products and heme spectra index antioxidant efficacy in kidney tissue of hamsters. Free Radic. Biol. Med. 1998, 24, 1278-1284.

43. Eldred, G.; Katz, M.L. The lipid peroxidation theory of lipofuscinogenesis cannot yet be confirmed. Free Radic. Biol. Med. 1991, 10, 445-447.

44. Greenberg, J.P.; Duncker, T.; Woods, R.L.; Smith, R.T.; Sparrow, J.R.; Delori, F.C. Quantitative fundus autofluorescence in healthy eyes. Invest. Ophthalmol. Vis. Sci. 2013, 54, 5684-5693. 
45. Ach, T.; Huisingh, C.; McGwin, G., Jr.; Messinger, J.D.; Zhang, T.; Bentley, M.J.; Gutierrez, D.B.; Ablonczy, Z.; Smith, R.T.; Sloan, K.R.; et al. Quantitative autofluorescence and cell density maps of the human retinal pigment epithelium. Invest. Ophthalmol. Vis. Sci. 2014, 55, 4832-4841.

46. Spaide, R.F. Autofluorescence imaging with the fundus camera. In Atlas of Fundus Autofluorescence Imaging, Holz, F.G., Schmitz-Valckenberg, S., Spaide, R.F., Bird, A.C., Eds.; Springer-Verlag: Berlin-Heidelberg, Germany, 2007; pp. 49-54.

47. Von Ruckmann, A.; Fitzke, F.W.; Bird, A.C. In vivo fundus autofluorescence in macular dystrophies. Arch. Ophthalmol. 1997, 115, 609-615.

48. Morgan, J.I.; Hunter, J.J.; Masella, B.; Wolfe, R.; Gray, D.C.; Merigan, W.H.; Delori, F.C.; Williams, D.R. Light-induced retinal changes observed with high-resolution autofluorescence imaging of the retinal pigment epithelium. Invest. Ophthalmol. Vis. Sci. 2008, 49, 3715-3729.

49. Sparrow, J.R.; Wu, Y.; Nagasaki, T.; Yoon, K.D.; Yamamoto, K.; Zhou, J. Fundus autofluorescence and the bisretinoids of retina. PhotoChem. PhotoBiol. Sci. 2010, 9, 1480-1489.

50. Eldred, G.E.; Miller, G.V.; Stark, W.S.; Feeney-Burns, L. Lipofuscin: Resolution of discrepant fluorescence data. Science 1982, 216, 757-758.

51. Boulton, M.; Docchio, F.; Dayhaw-Barker, P.; Ramponi, R.; Cubeddu, R. Age-related changes in the morphology, absorption and fluorescence of melanosomes and lipofuscin granules of the retinal pigment epithelium. Vis. Res. 1990, 30, 1291-1303.

52. Feeney-Burns, L.; Eldred, G.E. The fate of the phagosome: Conversion to "age pigment" and impact in human retinal pigment epithelium. Trans. Ophthalmol. Soc. UK 1983, 103, 416-421.

53. Rozanowska, M.; Jarvis-Evans, J.; Korytowski, W.; Boulton, M.E.; Burke, J.M.; Sarna, T. Blue light-induced reactivity of retinal age pigment. In vitro generation of oxygen-reactive species. J. Biol. Chem. 1995, 270, 18825-18830.

54. Boulton, M.; Dontsov, A.; Jarvis-Evans, J.; Ostrovsky, M.; Svistunenko, D. Lipofuscin is a photoinducible free radical generator. J. PhotoChem. PhotoBiol. B 1993, 19, 201-204.

55. Gaillard, E.R.; Atherton, S.J.; Eldred, G.; Dillon, J. Photophysical studies on human retinal lipofuscin. PhotoChem. PhotoBiol. 1995, 61, 448-453.

56. Ben-Shabat, S.; Itagaki, Y.; Jockusch, S.; Sparrow, J.R.; Turro, N.J.; Nakanishi, K. Formation of a nona-oxirane from $\mathrm{A} 2 \mathrm{E}$, a lipofuscin fluorophore related to macular degeneration, and evidence of singlet oxygen involvement. Angew. Chem. Int. Ed. 2002, 41, 814-817.

57. Jang, Y.P.; Matsuda, H.; Itagaki, Y.; Nakanishi, K.; Sparrow, J.R. Characterization of peroxy-A2E and furan-A2E photooxidation products and detection in human and mouse retinal pigment epithelial cells lipofuscin. J. Biol. Chem. 2005, 280, 39732-39739.

58. Kim, S.R.; Jang, Y.P.; Jockusch, S.; Fishkin, N.E.; Turro, N.J.; Sparrow, J.R. The all-trans-retinal dimer series of lipofuscin pigments in retinal pigment epithelial cells in a recessive stargardt disease model. Proc. Natl. Acad. Sci. USA 2007, 104, 19273-19278.

59. Sparrow, J.R.; Zhou, J.; Ben-Shabat, S.; Vollmer, H.; Itagaki, Y.; Nakanishi, K. Involvement of oxidative mechanisms in blue light induced damage to A2E-laden RPE. Invest. Ophthalmol. Vis. Sci. 2002, 43, 1222-1227. 
60. Wu, Y.; Yanase, E.; Feng, X.; Siegel, M.M.; Sparrow, J.R. Structural characterization of bisretinoid A2E photocleavage products and implications for age-related macular degeneration. Proc. Natl. Acad Sci. USA 2010, 107, 7275-7280.

61. Gaillard, E.R.; Avalle, L.B.; Keller, L.M.M.; Wang, Z.; Reszka, K.J.; Dillon, J.P. A mechanistic study of the photooxidation of A2E, a component of human retinal lipofuscin. Exp. Eye Res. 2004, 79, 313-319.

62. Zhou, J.; Cai, B.; Jang, Y.P.; Pachydaki, S.; Schmidt, A.M.; Sparrow, J.R. Mechanisms for the induction of HNE- MDA- and AGE-adducts, RAGE and VEGF in retinal pigment epithelial cells. Exp. Eye Res. 2005, 80, 567-580.

63. Cano, M.; Fijalkowski, N.; Kondo, N.; Dike, S.; Handa, J. Advanced glycation endproduct changes to bruch's membrane promotes lipoprotein retention by lipoprotein lipase. Am. J. Pathol. 2011 179, 850-859

64. Crabb, J.W.; Miyagi, M.; Gu, X.; Shadrach, K.; West, K.A.; Sakaguchi, H.; Kamei, M.; Hasan, A.; Yan, L.; Raybourn, M.E.; et al. Drusen proteome analysis: An approach to the etiology of age-related macular degeneration. Proc. Natl. Acad. Sci. USA 2002, 99, 14682-14687.

65. Zhou, J.; Jang, Y.P.; Kim, S.R.; Sparrow, J.R. Complement activation by photooxidation products of A2E, a lipofuscin constituent of the retinal pigment epithelium. Proc. Natl. Acad. Sci. USA 2006, 103, 16182-16187.

66. Zhou, J.; Kim, S.R.; Westlund, B.S.; Sparrow, J.R. Complement activation by bisretinoid constituents of RPE lipofuscin. Invest. Ophthalmol. Vis. Sci. 2009, 50, 1392-1399.

67. Radu, R.A.; Hu, J.; Yuan, Q.; Welch, D.L.; Makshanoff, J.; Lloyd, M.; McMullen, S.; Travis, G.H.; Bok, D. Complement system dysregulation and inflammation in the retinal pigment epithelium of a mouse model for stargardt macular degeneration. J. Biol. Chem. 2011, 286, 18593-18601.

68. Wu, L.; Nagasaki, T.; Sparrow, J.R. Photoreceptor cell degeneration in $\mathrm{Abcr}^{-/}$mice. Adv. Exp. Med. Biol. 2010, 664, 533-539.

69. Radu, R.A.; Yuan, Q.; Hu, J.; Peng, J.H.; Lloyd, M.; Nusinowitz, S.; Bok, D.; Travis, G.H. Accelerated accumulation of lipofuscin pigments in the RPE of a mouse model for Abca4-mediated retinal dystrophies following vitamin a supplementation. Invest. Ophthalmol. Vis. Sci. 2008, 49, 3821-3829.

70. Wu, L.; Ueda, K.; Nagasaki, T.; Sparrow, J.R. Light damage in Abca4 and Rpe65rd12 mice. Invest. Ophthalmol. Vis. Sci. 2014, 55, 1910-1918.

71. Morgan, J.I.; Dubra, A.; Wolfe, R.; Merigan, W.H.; Williams, D.R. In vivo autofluorescence imaging of the human and macaque retinal pigment epithelial cell mosaic. Invest. Ophthalmol. Vis. Sci. 2009, 50, 1350-1359.

72. Yamamoto, K.; Zhou, J.; Hunter, J.J.; Williams, D.R.; Sparrow, J.R. Toward an understanding of bisretinoid autofluorescence bleaching and recovery. Invest. Ophthalmol. Vis. Sci. 2012, 53, 3536-3544.

73. Pandya, V.B.; Franzco, I.H.; Franzco, A.P.H. Does unintentional macular translocation after retinal detachment repair influence visual outcome. Clin. Exp. Ophthalmol. 2012, 40, 88-92. 
74. Shiragami, C.; Shiraga, F.; Yamaji, H.; Fukuda, K.; Takagishi, M.; Morita, M.; Kishikami, T. Unintentional displacement of the retina after standard vitrectomy for rhegmatogenous retinal detachment. Ophthalmology 2010, 117, 86-92.

75. Mata, N.L.; Weng, J.; Travis, G.H. Biosynthesis of a major lipofuscin fluorophore in mice and humans with Abcr-mediated retinal and macular degeneration. Proc. Natl. Acad. Sci. USA 2000, 97, 7154-7159.

76. Boyer, N.P.; Higbee, D.; Currin, M.B.; Blakeley, L.R.; Chen, C.; Ablonczy, Z.; Crouch, R.K.; Koutalos, Y. Lipofuscin and $N$-retinylidene- $N$-retinylethanolamine (A2E) accumulate in the retinal pigment epithelium in the absence of light exposure: Their origin is 11-cis-retinal. J. Biol. Chem. 2012, 287, 22276-22286.

77. Quazi, F.; Molday, R.S. ATP-binding cassette transporter ABCA4 and chemical isomerization protect photoreceptor cells from the toxic accumulation of excess 11-cis-retinal. Proc. Natl. Acad. Sci. USA 2014, 111, 5024-5029.

78. Weiter, J.J.; Delori, F.C.; Wing, G.L.; Fitch, K.A. Retinal pigment epithelial lipofuscin and melanin and choroidal melanin in human eyes. Invest. Ophthalmol. Vis. Sci. 1986, 27, 145-151.

79. Delori, F.; Greenberg, J.P.; Woods, R.L.; Fischer, J.; Duncker, T.; Sparrow, J.; Smith, R.T. Quantitative measurements of autofluorescence with the scanning laser ophthalmoscope. Invest. Ophthalmol. Vis. Sci. 2011, 52, 9379-9390.

80. Ablonczy, Z.; Higbee, D.; Grey, A.C.; Koutalos, Y.; Schey, K.L.; Crouch, R.K. Similar molecules spatially correlate with lipofuscin and $N$-retinylidene- $N$-retinylethanolamine in the mouse but not in the human retinal pigment epithelium. Arch. BioChem. Biophys. 2013, 539, 196-202.

81. Grey, A.C.; Crouch, R.K.; Koutalos, Y.; Schey, K.L.; Ablonczy, Z. Spatial localization of A2E in the retinal pigment epithelium. Invest. Ophthalmol. Vis. Sci. 2011, 52, 3926-3933.

82. Feeney-Burns, L.; Hilderbrand, E.S.; Eldridge, S. Aging human RPE: Morphometric analysis of macular, equatorial, and peripheral cells. Invest. Ophthalmol. Vis. Sci. 1984, 25, 195-200.

83. Feeney, L. Lipofuscin and melanin of human retinal pigment epithelium. Fluorescence, enzyme cytochemical and ultrastructural studies. Invest. Ophthalmol. Vis. Sci. 1978, 17, 583-600.

84. Kellner, U.; Kellner, S.; Weinitz, S. Fundus autofluorescence (488 nm) and near-infrared autofluorescence $(787 \mathrm{~nm})$ visualize different retinal pigment epithelium alterations in patients with age-related macular degeneration. Retina 2010, 30, 6-15.

85. Cideciyan, A.V.; Swider, M.; Aleman, T.S.; Roman, M.I.; Sumaroka, A.; Schwartz, S.B. Reduced-illuminance autofluorescence imaging in ABCA4-associated retinal degenerations. J. Opt. Soc. Am. A Opt. Image Sci. Vis. 2007, 24, 1457-1467.

86. Keilhauer, C.N.; Delori, F.C. Near-infrared autofluorescence imaging of the fundus: Visualization of ocular melanin. Invest. Ophthalmol. Vis. Sci. 2006, 47, 3556-3564.

87. Huang, Z.; Zeng, H. Cutaneous melanin exhibiting fluorescence emission under near-infrared light excitation. J. Biomed. Optics 2006, 11, 34010.

88. Von Ruckmann, A.; Fitzke, F.W.; Bird, A.C. Fundus autofluorescence in age-related macular disease imaged with a laser scanning ophthalmoscope. Invest. Ophthalmol. Vis. Sci. 1997, 38, $478-486$. 
89. Boon, C.J.; van Schooneveld, M.J.; den Hollander, A.I.; van Lith-Verhoeven, J.J.; Zonneveld-Vrieling, M.N.; Theelen, T.; Cremers, F.P.; Hoyng, C.B.; Klevering, B.J. Mutations in the peripherin/RDS gene are an important cause of multifocal pattern dystrophy simulating STGD1/fundus flavimaculatus. Br. J. Ophthalmol. 2007, 91, 1504-1511.

90. Kellner, U.; Kellner, S.; Weber, B.H.; Fiebig, B.; Weinitz, S.; Ruether, K. Lipofuscin- and melanin-related fundus autofluorescence visualize different retinal pigment epithelial alterations in patients with retinitis pigmentosa. Eye (Lond.) 2009, 23, 1349-1359.

91. Robson, A.G.; Saihan, Z.; Jenkins, S.A.; Fitzke, F.W.; Bird, A.C.; Webster, A.R.; Holder, G.E. Functional characterisation and serial imaging of abnormal fundus autofluorescence in patients with retinitis pigmentosa and normal visual acuity. Br. J. Ophthalmol. 2006, 90, 472-479.

92. Michaelides, M.; Gaillard, M.C.; Escher, P.; Tiab, L.; Bedell, M.; Borruat, F.X.; Barthelmes, D.; Carmona, R.; Zhang, K.; White, E.; et al. The PROM1 mutation p.R373C causes an autosomal dominant bull's eye maculopathy associated with Rod, Rod-Cone, and macular dystrophy. Invest. Ophthalmol. Vis. Sci. 2010, 51, 4771-4780.

93. Gelman, R.; Chen, R.; Blonska, A.; Barile, G.; Sparrow, J.R. Fundus autofluorescence imaging in a patient with rapidly developing scotoma. Retinal Cases Brief Rep. 2012, 6, 345-348.

94. Holz, F.G.; Bellman, C.; Staudt, S.; Schutt, F.; Volcker, H.E. Fundus autofluorescence and development of geographic atrophy in age-related macular degeneration. Invest. Ophthalmol. Vis. Sci. 2001, 42, 1051-1056.

95. Schmitz-Valckenberg, S.; Jorzik, J.; Unnebrink, K.; Holz, F.G. Analysis of digital scanning laser ophthalmoscopy fundus autofluorescenceimages of geographic atrophy in advanced age-related macular degeneration. Graefe's Arch. Clin Exp. Ophthalmol. 2002, 240, 73-78.

96. Fleckenstein, M.; Issa, P.C.; Helb, H.M.; Schmitz-Valckenberg, S.; Finger, R.P.; Scholl, H.P.N.; Loeffler, K.U.; Holz, F.G. High-resolution spectral domain-OCT imaging in geographic atrophy associated with age-related macular degeneration. Invest. Ophthalmol. Vis. Sci. 2008, 49, 4137-4144.

97. Forte, R.; Querques, G.; Querques, L.; Massamba, N.; Le Tien, V.; Souied, E.H. Multimodal imaging of dry age-related macular degeneration. Acta Ophthalmol. 2012, 90, doi:10.1111/j.1755-3768.2011.02331.x.

98. Pilotto, E.; Guidolin, F.; Convento, E.; Spedicato, L.; Vujosevic, S.; Cavarzeran, F.; Midena, E. Fundus autofluorescence and microperimetry in progressing geographic atrophy secondary to age-related macular degeneration. Br. J. Ophthalmol. 2013, 97, 622-626.

99. Querques, G.; Querques, L.; Forte, R.; Massamba, N.; Blanco, R.; Souied, E.H. Precursors of type 3 neovascularization: A multimodal imaging analysis. Retina 2013, 33, 1241-1248.

100. Peng, Q.; Dong, Y.; Zhao, P.Q. Fundus autofluorescence in exudative age-related macular degeneration. Genet. Mol. Res.: GMR 2013, 12, 6140-6148.

101. Bindewald, A.; Bird, A.C.; Dandekar, S.S.; Dolar-Szczasny, J.; Dreyhaupt, J.; Fitzke, F.W.; Einbock, W.; Holz, F.G.; Jorzik, J.J.; Keilhauer, C.; et al. Classification of fundus autofluorescence patterns in early age-related macular disease. Invest. Ophthalmol. Vis. Sci. 2005, 46, 3309-3314. 
102. Bindewald, A.; Schmitz-Valckenberg, S.; Jorzik, J.J.; Dolar-Szczasny, J.; Sieber, H.; Keilhauer, C.; Weinberger, A.W.; Dithmar, S.; Pauleikhoff, D.; Mansmann, U.; et al. Classification of abnormal fundus autofluorescence patterns in the junctional zone of geographic atrophy in patients with age related macular degeneration. Br. J. Ophthalmol. 2005, 89, 874-878.

103. Holz, F.G.; Bindewald-Wittich, A.; Fleckenstein, M.; Dreyhaupt, J.; Scholl, H.P.; Schmitz-Valckenberg, S.; Group, F.-S. Progression of geographic atrophy and impact of fundus autofluorescence patterns in age-related macular degeneration. Am. J. Ophthalmol. 2007, 143, $463-472$.

104. Skondra, D.; Papakostas, T.D.; Hunter, R.; Vavvas, D.G. Near infrared autofluorescence imaging of retinal diseases. Semin. Ophthalmol. 2012, 27, 202-208.

105. Querques, L.; Querques, G.; Forte, R.; Souied, E.H. Microperimetric correlations of autofluorescence and optical coherence tomography imaging in dry age-related macular degeneration. Am. J. Ophthalmol. 2012, 153, 1110-1115.

106. Dowling, J.E.; Sidman, R.L. Inherited retinal dystrophy in the rat. J. Cell Biol. 1962, 14, 73-109.

107. Matthes, M.T.; La Vail, M.M. Inherited retinal dystrophy in the RCS rat: Composition of the outer segment debris zone. Prog. Clin. Biol. Res. 1989, 314, 315-330.

108. D’Cruz, P.M.; Yasumura, D.; Weir, J.; Matthes, M.T.; Abderrahim, H.; La Vail, M.M.; Vollrath, D. Mutation of the receptor tyrosine kinase gene mertk in the retinal dystrophic RCS rat. Hum. Mol. Genet. 2000, 9, 645-651.

109. Schmitz-Valckenberg, S.; Bultmann, S.; Dreyhaupt, J.; Bindewald, A.; Holz, F.G.; Rohrschneider, K. Fundus autofluorescence and fundus perimetry in the junctional zone of geographic atrophy in patients with age-related macular degeneration. Invest. Ophthalmol. Vis. Sci. 2004, 45, 4470-4476.

110. Wolf-Schnurrbusch, U.E.K.; Enzmann, V.; Brinkmann, C.K.; Wolf, S. Morphological changes in patients with geographic atrophy assessed with a novel spectral OCT-SLO combination. Invest. Ophthalmol. Vis. Sci. 2008, 49, 3095-3099.

111. Maeda, A.; Maeda, T.; Sun, W.; Zhang, H.; Baehr, W.; Palczewski, K. Redundant and unique roles of retinol dehydrogenases in the mouse retina. Proc. Natl. Acad. Sci. USA 2007, 104, 19565-19570.

112. Yeh, S.; Hwang, T.S.; Weleber, R.G.; Watzke, R.C.; Francis, P.J. Acute macular outer retinopathy (AMOR): A reappraisal of acute macular neuroretinopathy using multimodality diagnostic testing. Arch. Ophthalmol. 2011, 129, 365-368.

113. Rudolf, M.; Vogt, S.D.; Curcio, C.A.; Huisingh, C.; McGwin, G.J.; Wagner, A.; Grisanti, S.; Read, R.W. Histologic basis of variations in retinal pigment epithelium autofluorescence in eyes with geographic atrophy. Ophthalmology 2013, 120, 821-828.

114. Sparrow, J.R.; Yoon, K.; Wu, Y.; Yamamoto, K. Interpretations of fundus autofluorescence from studies of the bisretinoids of retina. Invest. Ophthalmol. Vis. Sci. 2010, 51, 4351-4357.

115. Schmitz-Valckenberg, S.; Lara, D.; Nizari, S.; Normando, E.M.; Guo, L.; Wegener, A.R.; Tufail, A.; Fitzke, F.W.; Holz, F.G.; Cordeiro, M.F. Localisation and significance of in vivo near-infrared autofluorescent signal in retinal imaging. Br. J. Ophthalmol. 2011, 95, 1134-1139.

116. Feeney-Burns, L.; Berman, E.R.; Rothman, H. Lipofuscin of human retinal pigment epithelium. Am. J. Ophthalmol. 1980, 90, 783-791. 
117. Duncker, T.; Tabacaru, M.R.; Lee, W.; Tsang, S.H.; Sparrow, J.R.; Greenstein, V.C. Comparison of near-infrared and short-wavelength autofluorescence in retinitis pigmentosa. Invest. Ophthalmol. Vis. Sci. 2013, 54, 585-591.

118. Duncker, T.; Tsang, S.H.; Lee, W.; Zernant, J.; Allikmets, R.; Delori, F.C.; Sparrow, J.R. Quantitative fundus autofluorescence distinguishes ABCA4-associated and non-ABCA4-associated bull's-eye maculopathy. Ophthalmology 2014, doi:10.1016/j.ophtha.2014.08.017.

119. Duncker, T.; Marsiglia, M.; Lee, W.; Zernant, J.; Tsang, S.H.; Allikmets, R.; Greenstein, V.C.; Sparrow, J.R. Correlations amongst near-infrared and short-wavelength autofluorescence and spectral domain optical coherence tomography in recessive stargardt disease. Invest. Ophthalmol. Vis. Sci. 2014, doi:10.1167/iovs.14-14848.

120. Wong, I.Y.; Iu, L.P.; Koizumi, H.; Lai, W.W. The inner segment/outer segment junction: What have we learnt so far? Curr. Opin. Ophthalmol. 2012, 23, 210-218.

(C) 2014 by the authors; licensee MDPI, Basel, Switzerland. This article is an open access article distributed under the terms and conditions of the Creative Commons Attribution license (http://creativecommons.org/licenses/by/4.0/). 